Reprod. Nutr. Dévelop., 1985, 25 (1 B), 287-293.

\title{
Activité lipoprotéine-lipasique de différents dépôts adipeux, et ses relations avec la taille des adipocytes chez la vache tarie en cours d'engraissement, ou en début de lactation
}

\author{
Y. CHILLIARD, J. ROBELIN (*) \\ avec la collaboration technique de Jeanne FLECHET et Christiane BARBOIRON (*) \\ Laboratoire de la Lactation. \\ (*) Laboratoire de la Production de Viande, \\ I.N.R.A., Theix, 63122 Ceyrat, France.
}

Summary. Lipoprotein lipase activity in various adipose tissues and its relationship with adipocyte size in cows during fattening or in early lactation.

Twelve dry and eight lactating cows were slaughtered and the whole body was chemically analysed. Adipose tissue lipid and adipose cell size varied greatly with body condition and also with anatomical site (perirenal, omental, intermuscular, rump subcutaneous, leg subcutaneous). Lipoprotein lipase activity per adipose cell was very low in lactating cows, but very high in dry cows during fattening. Activity tended to be higher in omental adipose tissue and lower in subcutaneous adipose tissue. Total adipose lipoprotein lipase activity per cow was positively related with energy balance and negatively related with plasma non-esterified fatty acids. There was no correlation with body fatness or adipose cellularity.

\section{Introduction.}

II n'existe que peu d'études sur l'activité lipoprotéine-lipasique (LPL) des différents tissus adipeux chez les bovins adultes (Rao et Hawkins, 1976). Cette enzyme intervient dans le dépôt lipidique au niveau du prélèvement des lipides sanguins. L'objet de la présente étude est de préciser les relations pouvant exister entre l'activité LPL, le poids, et la cellularité de différents dépôts adipeux, et l'état nutritionnel de vaches en cours d'engraissement ou en début de lactation.

\section{Matériel et méthodes.}

Dans un premier essai, trois lots de 4 vaches Holstein $\times$ Frisonnes taries ont été constitués ; les animaux du lot l ont été abattus au début de l'essai alors qu'ils recevaient $7 \mathrm{~kg}$ de foin, et ceux des lots II et III ont reçu une alimentation libérale 
(10 kg de matière sèche d'ensilage de maîs $+330 \mathrm{~g}$ de tourteau de soja par jour) durant 49 jours (lot II) et 155 jours (lot III), avant d'être abattus (Robelin, 1982).

Dans un second essai, un groupe de 4 vaches de même génotype a été abattu 5 jours après le vêlage (lot IV) et un autre groupe de 4 vaches après 8 semaines de lactation (lot $\mathrm{V}$ ). Durant cette période, les animaux du lot $\mathrm{V}$ ont reçu une ration déficitaire par rapport à leurs besoins.

Dans les deux essais on a contrôlé les quantités ingérées, la digestibilité des rations, et éventuellement les quantités et la composition du lait produit, afin de calculer le bilan énergétique des animaux pendant la semaine précédant l'abattage. On a également mesuré les teneurs en acides gras non-estérifiés plasmatiques, selon la méthode de Trout, Estes et Friedberg (1960).

Après abattage, le corps entier des animaux a été disséqué, les différents tissus et organes ont été pesés et leur composition chimique (eau, lipides, protéines, minéraux) déterminée. La taille des adipocytes des tissus adipeux périrénal, épiplö̈que, intermusculaire, sous-cutané des membres et sous-cutané de la croupe a été mesurée comme décrit par Robelin (1981). L'activité LPL d'homogénats aqueux des mêmes tissus a été déterminée comme indiqué par Chilliard, Dorléans et Fehr (1977), mais en mesurant les acides gras libérés par la méthode de Trout, Estes et Friedberg (1960).

\section{Résultats et discussion.}

Les vaches des lots I et $V$ étaient très maigres, et celles des lots III et IV très grasses (tabl. 1). Les variations du poids de lipides des dépôts adipeux totaux (allant de 1 à 6 entre les vaches maigres et grasses) sont dues essentiellement à des variations parallèles du volume des adipocytes de différents sites anatomiques (tabl. 1), alors que le nombre d'adipocytes par dépôt est stable (Robelin et Chilliard, 1984).

Pour un état d'engraissement donné, les dépôts adipeux internes tendent à avoir des adipocytes de plus grand volume, et les dépôts sous-cutanés, des adipocytes de plus petit volume, en accord avec les résultats obtenus chez les bovins de race Frisonne en croissance (Robelin, 1985). Ces différences entre sites sont toutefois moins nettes chez les vaches en lactation (lots IV et V) que chez les vaches taries (lots I, II, III). Le protocole utilisé ne permet pas, toutefois, de savoir si ces variations dans la hiérarchie des volumes d'adipocytes entre sites anatomiques sont dues à l'état physiologique des animaux ou à des différences individuelles.

L'activité LPL par adipocyte est presque nulle dans les différents sites anatomiques étudiés chez les vaches des lots I, IV et $V$ (tabl. 2). Par contre, elle est élevée chez les animaux du lot III, et surtout du lot II. Les activités LPL ne sont donc reliées ni au poids ni à la cellularité des dépôts adipeux correspondants.

Chez les animaux des lots II et III, les activités LPL les plus élevées sont enregistrées dans le tissu adipeux épiploïque, et les plus basses dans le tissu adipeux sous-cutané des membres. Ces différences ne sont toutefois que rarement significatives en raison des faibles effectifs et des grandes variations individuelles. Ce résul- 


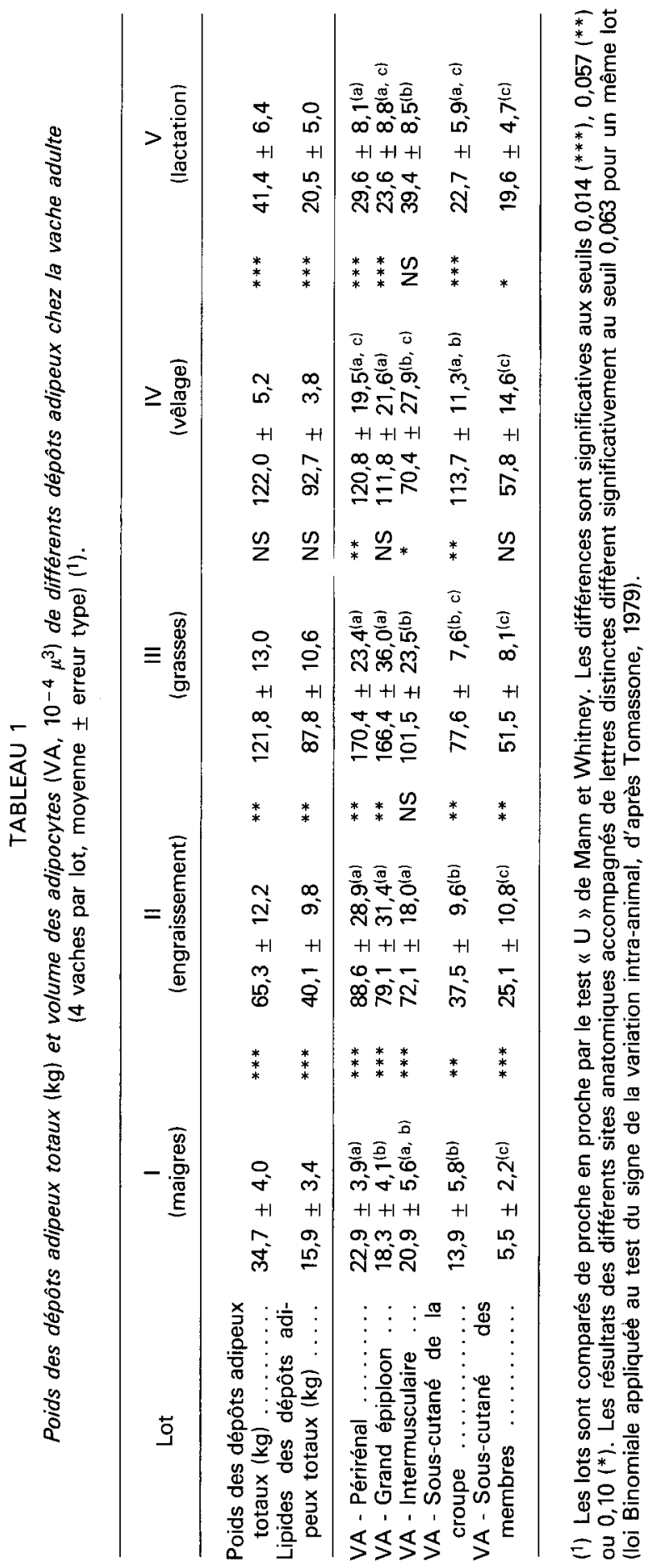




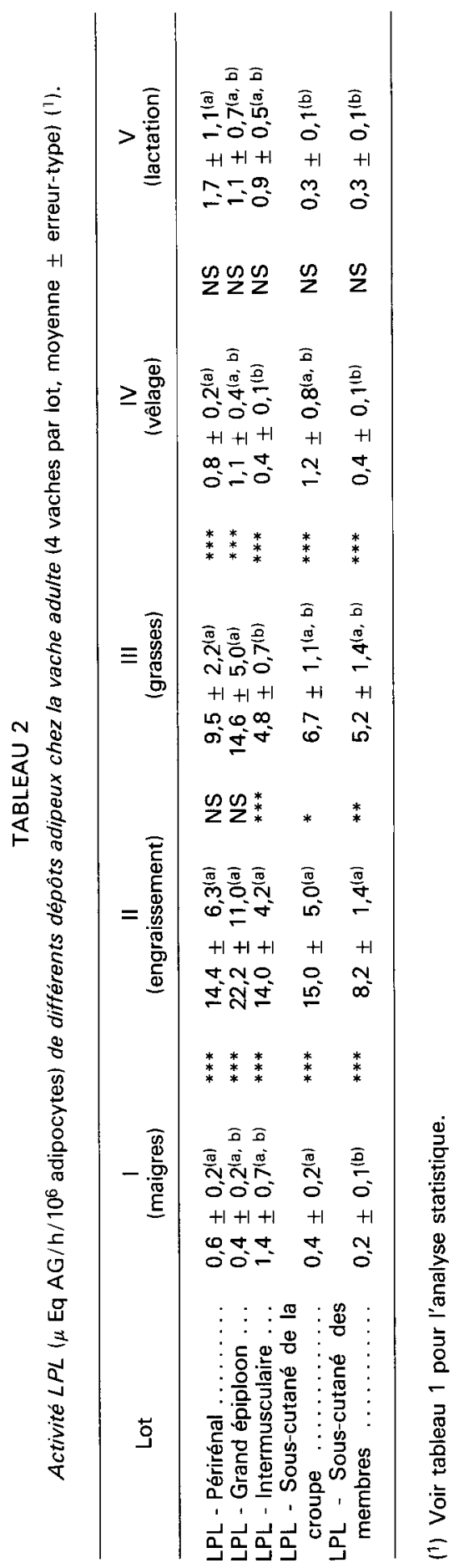


tat est en accord avec, et précise les données obtenues chez le bceuf (Rao et Hawkins, 1976) et la chèvre laitière (Chilliard et al., 1981).

L'activité LPL totale des tissus adipeux d'un animal a été calculée en tenant compte du poids des différents tissus, et en supposant que les activités spécifiques (LPL/gramme) des sites étudiés étaient représentatives des autres sites de même nature (internes, intermusculaires ou sous-cutanés). Cette activité varie parallèlement au bilan énergétique des animaux taris (lots I, II, III), qui ont des bilans positifs ou équilibrés (tabl. 3). Par contre, chez les animaux dont le bilan est fortement négatif (lots IV et V), l'activité LPL est presque nulle quelle que soit l'amplitude du déficit énergétique. II en résulte que les teneurs en acides gras non estérifiés plasmatiques semblent être un peu mieux reliées au bilan énergétique que l'activité LPL lorsqu'on considère l'ensemble des 20 vaches étudiées (tabl. 3 ). Au niveau individuel, l'activité LPL est toujours inférieure à 200000 unités par vache lorsque les teneurs en acides gras non estérifiés plasmatiques sont supérieures à $300 \mu \mathrm{M}$ (11 vaches), et toujours supérieure à 500000 unités lorsque les teneurs en acides gras non estérifiés sont inférieures à $250 \mu \mathrm{M}$ (8 vaches) (fig. 1). La relation hyperbolique qui existe entre ces 2 variables confirme qu'anabolisme et lipomobilisation intenses s'excluent mutuellement dans les tissus adipeux; elle

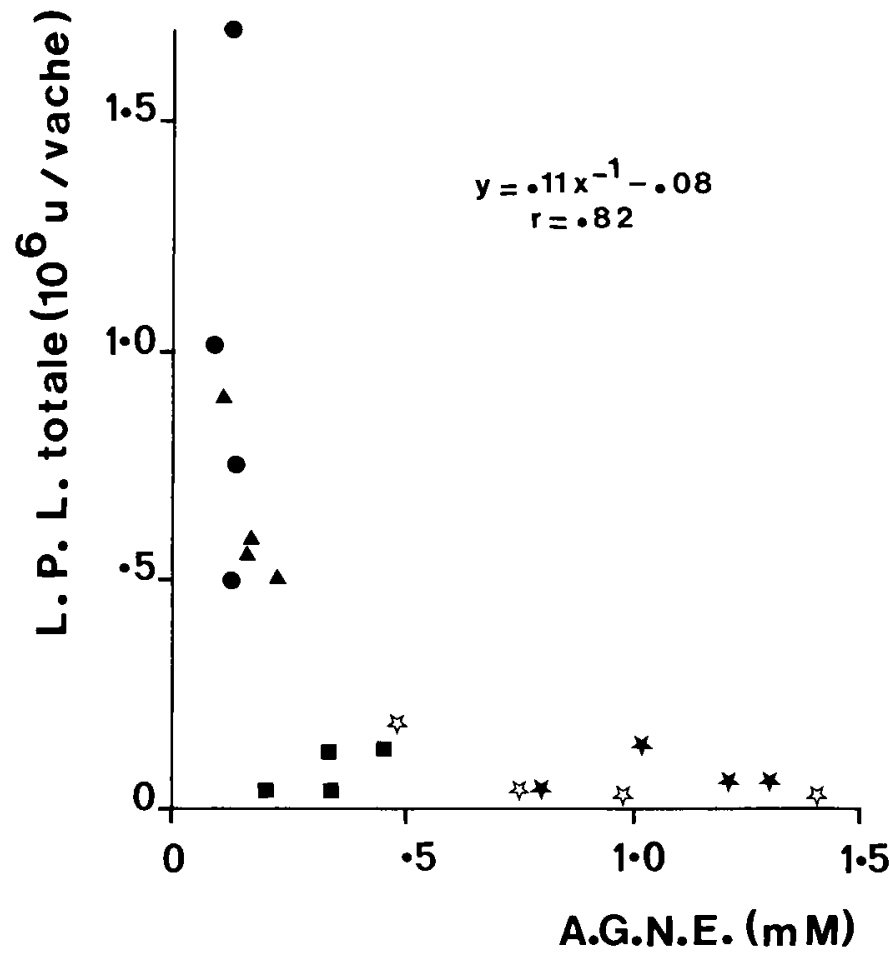

FIG. 1. - Relation entre l'activité LPL totale des dépôts adipeux (106 unités par vache) et la teneur en acides gras non estérifiés plasmatiques $(\mathrm{mM})$ chez 20 vaches.

( $\boldsymbol{\square}, \operatorname{lot} \mathrm{I} ; \boldsymbol{\bullet}, \operatorname{lot} \mathrm{II} ; \mathbf{\Delta}, \operatorname{lot} \mathrm{III} ; \star$, lot IV ; is, lot V). 


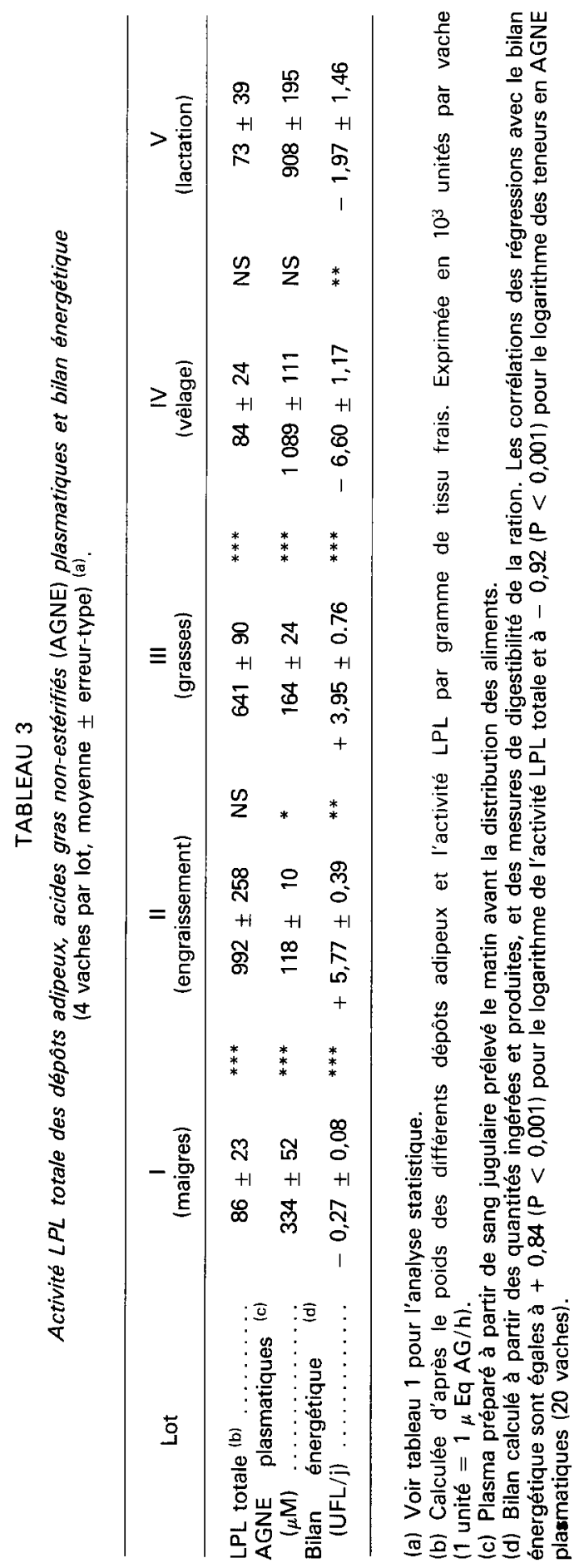


permet de préciser l'interprétation des teneurs en acides gras non estérifiés plasmatiques.

II semble qu'un pic d'activité LPL ait eu lieu au début de la période d'engraissement des vaches taries (lot II). Celui-ci correspond probablement à un dépôt lipidique intense puisque les activités d'enzymes (glucose-6-phosphate deshydrogénase et enzyme malique) impliquées dans la lipogenèse de novo présentent aussi un maximum à ce stade (Chilliard et Robelin, non publié). Le protocole expérimental utilisé ne permet pas de savoir si cet anabolisme est la cause ou la conséquence d'une efficacité d'utilisation de la ration plus élevée chez les animaux du lot II.

Le très faible niveau d'activité LPL et d'anabolisme lipidique des tissus adipeux observé chez les vaches des lots IV et $V$ est en accord avec les observations effectuées par ailleurs chez le ruminant laitier en début de lactation, qui mobilise alors plus ou moins intensément ses lipides corporels (revue de Chilliard et al., 1983).

10e Réunion du groupe Développement, I.N.R.A., Rennes, 9-10 mai 1984.

\section{Références}

CHILLIARD Y., DORLÉANS M., FEHR P. M., 1977. Mise en évidence d'une activité lipoprotéinelipasique dans le tissu adipeux de chèvre : comparaison de trois méthodes d'extraction. Ann. Biol. anim. Bioch. Biophys., 17, 107-122.

CHILLIARD Y., RÉMOND B., SAUVANT D., VERMOREL M., 1983. Particularités du métabolisme énergétique. In Particularités nutritionnelles des vaches à haut potentiel de production. Bull. Tech., CRZV, Theix, INRA, 53, 37-64.

CHILLIARD Y., SAUVANT D., BAS P., PASCAL G., MORAND-FEHR P., 1981. Importance relative et activités métaboliques des différents tissus adipeux de la chèvre laitière. In Nutrition et systèmes d'alimentation de la chèvre, INRA-ITOVIC, Vol. 1, 80-89.

RAO D. R., HAWKINS G. E., 1976. Activity of lipoprotein lipase in adipose tissues from steers. J. Dairy Sci., 59, 161-163.

ROBELIN J., 1981. Cellularity of bovine adipose tissues: developmental changes from 15 to 65 percent mature weight. J. Lipid Res., 22, 452-457.

ROBELIN J., 1982. A note on the estimation in vivo of body fat in cows using deuterium oxide or adipose cell size. Anim. Prod., 34, 347-350.

ROBELIN J., 1985. Cellularité des différents dépôts adipeux des bovins en croissance (10e Journées du Groupe Développement de l'INRA). Reprod. Nutr. Dévelop., 25, 211-214.

ROBELIN J., CHILLIARD Y., 1984. Cellularité et activité LPL des différents dépôts chez la vache adulte en cours d'engraissement. 1'e Conf. annu. sur l'Obésité (AFERO). Paris, 23 mars 1984 (p. 8).

TOMASSONE R., 1979. Cours de statistique non paramétrique. Institut National Agronomique Paris-Grignon.

TROUT D. L., ESTES E. H., FRIEDBERG S. J., 1960. Titration of free fatty acids of plasma : a study of current methods and a new modification. J. Lipid Res., 1, 199-202. 